\title{
STUDYING INDICATORS OF GELATIN AND NATURAL POLYSACCHARIDES QUALITY AND SAFETY
}

\author{
Alexander Prosekov ${ }^{*}$, Lyudmila Asyakina, Lyubov Dyshlyuk \\ Federal State-owned Budgetary Educational Institution of Higher Vocational Education “Kemerovo State University”, 650000, Russia, Kemerovo, Red Street, 6
}

Received - December 13, 2017; Revision - March 02, 2018; Accepted - May 05, 2018

Available Online - June 20, 2018

DOI: http://dx.doi.org/10.18006/2018.6(3).582.591

KEYWORDS
Biodegradable polymers
Packaging
Gelatin
Carageenan
Hydroxypropymethylcellulose
Agar-agar

\begin{abstract}
Present study was conducted with the aim of finding out the optimal composition of biodegradable packaging materials based on gelatin and natural polysaccharides, film samples. The film samples have been obtained with the purpose of choosing the optimum composition of biodegradable packaging materials based on gelatin and natural polysaccharides. Physico-chemical properties and safety performance of gelatin and natural polysaccharides (agar, carrageenan, hydroxypropylmethicellulose HPMC) have been studied. Films based on gelatin and natural polysaccharides have been obtained by drying solutions of the tested components at various temperatures. Result of study revealed the fact that physico-chemical parameters of the studied samples of agar-agar and hydroxypropymethylcellulose (HPMC) confirmed to the requirements of normative documents. In terms of chemical and microbiological safety, both studied samples of agar-agar and carageenan satisfy the applicable regulatory requirements of the international food standard, and may be used as raw material for obtaining biodegradable polymers. It has been proved that the studied samples of carageenan meet the requirements of applicable normative documentation in their physical and chemical properties. It has been shown that in terms of quality and safety, all tested samples satisfied the requirements of the applicable documentation.
\end{abstract}

* Corresponding author

E-mail: elen.ulrich@mail.ru (Aleksander Prosekov)

Peer review under responsibility of Journal of Experimental Biology and Agricultural Sciences.

Production and Hosting by Horizon Publisher India [HPI] (http://www.horizonpublisherindia.in/).

All rights reserved.
All the article published by Journal of Experimental Biology and Agricultural Sciences is licensed under a Creative Commons Attribution-NonCommercial 4.0 International License Based on a work at www.jebas.org.

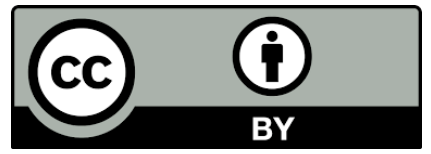




\section{Introduction}

Packaging materials used in food industry are subject to rigid requirements and it should strongly comply the requirements of technical regulation TR TS 005/2011 "About safety of packaging" (Kisku \& Swain, 2012; Schreiber et al. 2013). One of the mandatory conditions governing the use of packaging in food industry is the availability of a certificate of compliance issued by the Ministry of Health, which confirms packaging materials' safety for humans (Pantyukhov, 2012a; Khan et al., 2014; Pantyukhov, 2012a).

Currently, food industries and retailers who are widely using the packaging materials should not only ensure safety of the food products, but should also be economically viable and safe for human health and environment (Pantyukhov 2012b). Therefore, various sanitary-epidemiological and hygienic requirements are applied to packaging products (Lu et al., 2010). Among this, some most common are (i) the packaging should not change organoleptic and physico-chemical properties of food products (ii) the packaging should not emit harmful or toxic substances (Lu et al., 2010; Liu, 2010; Rhim, 2013; Liu, 2015; Razavi, 2016), (iii) the packaging should not contain substances that have cumulative, mutagenic, allergenic and carcinogenic properties, and other compounds that affect the state and health of a living organism (Rhim, 2013) and (iv) the packaging should not be the nutritional medium for pathogenic and other microflora, and should not let through microorganisms.

This document established the requirements of the quality and composition of the material used for packaging, packaging surface, size and quality of side seams, strength and integrity of packaging (Liu, 2010, Kisku \& Swain, 2012; Schreiber et al., 2013; Liu, 2015). This work is aimed to choose the optimum composition of biodegradable packaging materials based on gelatin and natural polysaccharides for obtaining films' samples and studying their properties.

\section{Materials and methods}

In present study gelatine and natural polysaccharides viz., agaragar, carrageenan and hydroxypropylmethylcellulose (HPMC) has been used as packageing material. Based on the performance, physico-chemical properties and safety indicators: agar-agar (Helicon, USA), Kappa-carageenan (Boc Sciences, USA), hydroxypropymethylcellulose (Ashland Aqualon Functional Ingredients, USA), and gelatin ("GelatinesWeishardt", France) have been selected.

Gelatin is a colorless or yellowish partially hydrolyzed collagen protein with a transparent viscous mass, without taste and smell. It is a product of animals 'connective tissues processing (denaturing). Further, gelatin couldn't dissolve in diluted acids and when it mixes with diluted acid it will swells. Swollen gelatin dissolves when heated and forming a solution which convert in jelly when solidifies (Rhim 2013).

Agar-agar is another gelatinous material which obtained from sea algae. Like gelatin it is also insoluble in cold water and can completely dissolve when heated at $85-95^{\circ} \mathrm{C}$. Molecules of Carageenan are large, highly flexible, and can form inter twisted structures. It can form various gels at room temperature. Hydroxypropy methyl cellulose is a stabilizer capable of maintaining and improving viscosity and consistency of food products (Rhim 2013).

Aiming to comprehensively study, various properties of the initial components for obtaining biodegradable polymers, their physicochemical properties and indicators of chemical and microbiological safety were studied. During the study normative technical documentation for certain kinds of natural polysaccharides and gelatin were taken into account:

- GOST 16280-2002 - Food agar - Specifications (Schreiber et al., 2013)

- $\quad$ Carageenan. CAS 11114-20-8 (Schreiber et al., 2013)

- Hydroxypropymethylcellulose - CAS 9004-65-3 (Schreiber et al., 2013)

- GOST 23058-89 - Gelatin as raw material for medical industry Specifications (Schreiber et al., 2013)

Mixture of Gelatin and other natural polysaccharides were aged in an autoclave in blowing mode for 15 minutes and films based on these were obtained by drying solutions of the tested components at various temperatures. The film-forming solution was transferred into a cuvette with (1-2) mm sides, which was covered with a glass cover. Then the solution was cooled at room temperature and one millimeter thick films were obtained by pouring. Film of the gelatin and other natural polysaccharides were dried up in various ways, among this some common are (i) drying at room temperature (ii) drying by air convection in a fume cabinet (iii) dried in a vacuum drying cabinet (the temperature of drying varied) and (iv) drying in a drying cabinet (the temperature of drying varied).

For obtaining transparent, flexible and uniform thickness films various combination of selected polysacharide have been tried. As per the used combinations, film number such as No. 3 (mix of $20 \%$ agar and $80 \%$ carrageenan), No. 11 (a mixture of $30 \%$ agar and $70 \%$ carrageenan), No. 20 (a mixture of $40 \%$ agar and $60 \%$ carrageenan), No. $14 \quad$ (a mixture of $20 \%$ hydroxypropylmethylcellulose and $80 \%$ gelatine), No. 16 (a mixture of $30 \%$ hydroxypropylmethylcellulose and $70 \%$ gelatin), 
and No. 18 (a mixture of 40\% hydroxypropylmethylcellulose and $60 \%$ gelatin) has been assigned. The mixture of components was kept on the heating mantle, the temperature of the mixer was 150 ${ }^{\circ} \mathrm{C}$, the rotation speed was $800 \mathrm{rpm}$; the resulting solution was poured on a substrate with sides $2 \mathrm{~mm}$ thick; drying was performed in a drying cabinet at $85^{\circ} \mathrm{C}$.

\section{Results}

Date given in table 1 represented the physico-chemical properties of the selected and processed two agar-agar samples (sample A1 and A2). Classification of agar-agar was carried out on the basis of manufacturers. On the basis of physicochemical properties and technical basis, both the selected agar-agar samples fulfill the requirement of GOST 16280-2002 for packaging materials. Results are in agreement with the findings and suggestions of Schreiber et al. (2013).

In physicochemical properties, agar-agar meets the criteria of GOST 16280-2002, in this study chemical and microbiological safety of agar-agar packaging material was also tested. Results of chemical and microbiological safety level of agar-agar have been represented in Table 2. Result of study revealed the presence of some heavy metals in agar-agar packaging material but contents of these heavy metals are not exceeding the maximum permissible concentration of GOST 16280-2002. During study presence of lead, cadmium, arsenic and mercury was reported. Presence of mesophilic aerobic and facultative anaerobic microorganisms was

Table 1 Physico-chemical properties of agar-agar

\begin{tabular}{|c|c|c|c|}
\hline \multirow{2}{*}{ Indicator name } & \multicolumn{2}{|c|}{ Sample } & \multirow{2}{*}{$\begin{array}{l}\text { Requirements of GOST } \\
16280-2002\end{array}$} \\
\hline & Sample A1 & Sample A2 & \\
\hline Gel strength with mass fractions of $0.85 \%$ dry agar and $70 \%$ sugar (g) & $1.650 \pm 165$ & $1.600 \pm 160$ & Not less than 1.600 \\
\hline $\begin{array}{l}\text { Loss of gel strength with the mass fraction of } 0.85 \% \text { dry agar after heating } \\
\text { the solution for } 2 \mathrm{~h}(\%)\end{array}$ & $10.0 \pm 1.0$ & $10.0 \pm 1.0$ & Not more than 10.0 \\
\hline Melting point of the gel with the mass fraction of $0.85 \%$ dry agar $\left({ }^{\circ} \mathrm{C}\right)$ & $82.0 \pm 8.2$ & $85.0 \pm 8.5$ & Not less than 80.0 \\
\hline $\begin{array}{l}\text { Gelatinization temperature of agar solution with the mass fraction of } \\
0.85 \% \text { dry agar }\left({ }^{\circ} \mathrm{C}\right)\end{array}$ & $32.0 \pm 3.2$ & $32.0 \pm 3.2$ & Not less than 30.0 \\
\hline $\begin{array}{l}\text { Gelatinization temperature of agar solution with the mass fraction of } \\
0.85 \% \text { dry agar and } 70 \% \text { sugar }\left({ }^{\circ} \mathrm{C}\right)\end{array}$ & $40.0 \pm 4.0$ & $42.0 \pm 4.2$ & Not more than 42.0 \\
\hline Mass fraction of water $(\%)$ & $16.0 \pm 1.6$ & $17.5 \pm 1.8$ & Not more than 18.0 \\
\hline Mass fraction of ash (\%) & $4.0 \pm 0.4$ & $4.2 \pm 0.4$ & Not more than 4.5 \\
\hline Presence of iodine & Not detected & Not detected & Not allowed \\
\hline Mass fraction of substances insoluble in hot water $(\%)$ & $0.20 \pm 0.02$ & $0.30 \pm 0.03$ & Not more than 0.40 \\
\hline
\end{tabular}

Here sample A1 - agar-agar made by Panreac (Germany); sample A2 - agar-agar made by Helicon (USA).

Table 2 Indicators of agar-agar chemical and microbiological safety

\begin{tabular}{|c|c|c|c|}
\hline \multirow{2}{*}{ Indicator name } & \multicolumn{2}{|c|}{ Sample } & \multirow{2}{*}{$\begin{array}{c}\text { Requirements of GOST } \\
16280-2002\end{array}$} \\
\hline & Sample A1 & Sample A2 & \\
\hline Lead $(\mathrm{mg} / \mathrm{kg})$ & $0.15 \pm 0.01$ & $0.08 \pm 0.01$ & not more than 2.00 \\
\hline Cadmium (mg/kg) & below the determination limit & $0.010 \pm 0.005$ & not more than 0.030 \\
\hline Arsenic $(\mathrm{mg} / \mathrm{kg})$ & $0.010 \pm 0.005$ & $0.010 \pm 0.005$ & no more than 0.500 \\
\hline Mercury (mg/kg) & below the determination limit & below the determination limit & not more than 0.02 \\
\hline $\begin{array}{l}\text { Mesophilic aerobic and facultative anaerobic } \\
\text { microorganisms (CFU/g) }\end{array}$ & $0.9 \cdot 102$ & $3.2 \cdot 102$ & not allowed \\
\hline $\begin{array}{l}\text { Coliform bacteria, } \\
\text { Proteus group bacteria }(\mathrm{CFU} / \mathrm{g})\end{array}$ & not found & not found & not allowed \\
\hline Pathogens & not found & not found & not allowed \\
\hline
\end{tabular}

Here sample A1 - agar-agar made by Panreac (Germany); sample A2 - agar-agar made by Helicon (USA). 
also reported during the study which is against the recommendation of GOST 16280-2002. Presence of coliforms, proteus group bacteria and pathogenic microorganisms was not reported from the agar-agar.

Results of physico-chemical properties of two carrageenan samples (K1 and K2) obtained from various manufacturers have been presented in Table 3. The results were analyzed in accordance with the requirements of the CODEX Alimentarius international standard for food products, CAS 11114-20-8. Result of study suggested that physico-chemical parameters of two selected carrageenan samples from various manufacturers did not exceed the values specified by CAS 11114-20-8. In this manner, in physicochemical characteristics, carageenan can be used as a packaging material.

Further, the results of testing carageenan chemical and microbiological safety, including the contents of heavy metals and the microbiological parameters have been shown in Table 4. Data given in the table revealed that both the samples of carrageenan meet the safety requirements of CAS 11114-20-8 in physicochemical and microbial properties. The contents of lead, cadmium, arsenic, mercury, mesophilic aerobic and facultative anaerobic microorganisms, coliforms, bacteria of group proteus, and pathogenic microorganisms did not exceed the maximum permissible concentration suggested by CsAS 11114-20-8.

Results of studied physicochemical parameters of two HPMC samples (samples G1 and G2) obtained from various manufacturers are shown in Table 5. Results were analyzed according to the requirements of the CODEX Alimentarius international standard (CAS 9004-65-3) for food products. The data in Table 5 shown that physico-chemical parameters two samples of HPMC did not exceed the values specified for packaging

Table 3 Physico-chemical characteristics of carageenan

\begin{tabular}{|lccc|}
\hline \multicolumn{1}{|c}{ Indicator name } & Sample & Requirements of CAS 11114-20-8 \\
\hline Mass fraction of moisture (\%) & $10.5 \pm 1.0$ & Sample K2 & Not more than 12.0 \\
\hline pH of the 1:100 suspension & $9.5 \pm 1.0$ & $11.0 \pm 1.1$ & $8.0-11.0$ \\
\hline Viscosity of a $1.5 \%$ solution at $75^{\circ} \mathrm{C}(\mathrm{cPs})$ & $6.5 \pm 0.3$ & $5.5 \pm 0.3$ & Not less than 5.0 \\
\hline Mass fraction of sulfates $(\%)$ & $25.0 \pm 2.5$ & $18.0 \pm 1.8$ & $15.0-40.0$ \\
\hline Mass fraction of ash $(\%)$ & $15.0 \pm 1.5$ & $17.5 \pm 1.8$ & $15.0-40.0$ \\
\hline Mass fraction of ash insoluble in acid $(\%)$ & $0.80 \pm 0.08$ & $0.50 \pm 0.05$ & No more than 1.00 \\
\hline $\begin{array}{l}\text { Mass fraction of substance insoluble in } \\
\text { acid }(\%)\end{array}$ & $1.0 \pm 0.1$ & $1.5 \pm 0.2$ & Not more than 2.0 \\
\hline Mass fraction of solvent, $(\%)$ & not found & $0.050 \pm 0.005$ & Not more than 0.100 \\
\hline
\end{tabular}

Note: sample K1 - Kappa-carageenan made by BocSciences (USA); sample K2 - iota-carageenan made by Newgreen Pharmchem Co. (China)

Table 4 Indicators of chemical and microbiological safety of carageenan

\begin{tabular}{|lccc|}
\hline \multicolumn{1}{|c}{ Indicator name } & Sample & Requirements of CAS 11114-20-8 \\
\hline Lead $(\mathrm{mg} / \mathrm{Kg})$ & Sample K1 & $1.10 \pm 0.06$ & Not more than 5.0 \\
\hline Arsenic $(\mathrm{mg} / \mathrm{Kg})$ & $0.50 \pm 0.03$ & $0.50 \pm 0.03$ & Not more than 3.0 \\
\hline Cadmium $(\mathrm{mg} / \mathrm{Kg})$ & $0.10 \pm 0.01$ & $0.10 \pm 0.01$ & Not more than 2.0 \\
\hline Mercury $(\mathrm{mg} / \mathrm{Kg})$ & not found & not found & Not more than 1.0 \\
\hline MAFAM $(\mathrm{CFU} / \mathrm{g})$ & $1.0 \cdot 10^{2}$ & $1.5 \cdot 10^{1}$ & Not more than $5.0 \cdot 10^{3}$ \\
\hline Pathogens & not found & not found & Not allowed \\
\hline Coliform bacteria $(\mathrm{CFU} / \mathrm{g})$ & not found & not found & Not allowed \\
\hline
\end{tabular}

Note: sample K1 - Kappa-carageenan made by BocSciences (USA); sample K2 - iota-carageenan made by Newgreen Pharmchem Co. (China) 
Table 5 Physico-chemical characteristics of HPMC

\begin{tabular}{|c|c|c|c|}
\hline \multirow{2}{*}{ Indicator name } & \multicolumn{2}{|c|}{ Sample } & \multirow{2}{*}{$\begin{array}{l}\text { Requirements of CAS } \\
\quad 9004-65-3\end{array}$} \\
\hline & Sample G1 & Sample G2 & \\
\hline Mass fraction of ash in terms of dry gelatin (\%) & $1.0 \pm 0.1$ & $0.9 \pm 0.1$ & not more than 1.5 \\
\hline Decreased viscosity of the solution with the mass fraction of gelatin at $10 \%(\%)$ & $11.5 \pm 0.6$ & $12.0 \pm 0.6$ & not more than 15.0 \\
\hline $\begin{array}{l}\text { Dynamic viscosity of a solution with the mass fraction of gelatin of } 10 \% \text {, in terms } \\
\text { of absolutely dry gelatin (MPa } s \text { ) }\end{array}$ & $25.0 \pm 1.2$ & $26.5 \pm 1.3$ & not less than 24.6 \\
\hline $\begin{array}{l}\text { Strength of jelly with the mass fraction of gelatin of } 10 \% \text {, in terms of absolutely } \\
\text { dry ash-free gelatin }(\mathrm{N} \mathrm{gs})\end{array}$ & $14.7 \pm 0.7$ & $15.0 \pm 0.8$ & Not less than 13.0 \\
\hline Transparency of the solution with the mass fraction of gelatin of $5 \%(\%)$ & $75.0 \pm 3.8$ & $80.0 \pm 4.0$ & Not less than 70.0 \\
\hline $\begin{array}{l}\text { The melting point of the jelly with the mass fraction of gelatin of } 10 \% \text {, in terms } \\
\text { of absolutely dry ash-free gelatin }\left({ }^{\circ} \mathrm{C}\right)\end{array}$ & $33.0 \pm 1.7$ & $35.2 \pm 1.8$ & not less than 32.0 \\
\hline $\mathrm{pH}$ of the solution with mass share of gelatin of $1 \%$ & $5.5 \pm 0.5$ & $5.7 \pm 0.6$ & $5.2-6.1$ \\
\hline
\end{tabular}

Here, sample G1 - HPMC made by Acros (Belgium); sample G2 - HPMC made by Ashland Aqualon Functional Ingredients (USA)

Table 6 Indicators of chemical and microbiological safety of hydroxypropymethylcellulose (HPMC)

\begin{tabular}{|c|c|c|c|}
\hline Indicator name & sample G1 & $\begin{array}{l}\text { e } \\
\text { sample G2 }\end{array}$ & Requirements of CAS 9004-65-3 \\
\hline Mass fraction of moisture (\%) & $8.0 \pm 0.8$ & $8.5 \pm 0.9$ & Not more than 10.0 \\
\hline $\mathrm{pH}$ of the $1: 100$ solution & 6.5 & 7.0 & $5.0-8.0$ \\
\hline Mass fraction of sulfated ash (\%) & $1.2 \pm 0.1$ & $1.5 \pm 0.1$ & $\begin{array}{l}\text { Not more than } 1.5 \text { for samples with the viscosity of } 50 \mathrm{cPs} \text { and higher. } \\
\text { Not more than } 3.0 \text { for samples with the viscosity less than } 50 \mathrm{cPs}\end{array}$ \\
\hline $\begin{array}{l}\text { Mesophilic aerobic and facultative } \\
\text { anaerobic microorganisms (CFU/g) }\end{array}$ & not found & not found & Not allowed \\
\hline Pathogens, including Salmonella & not found & not found & Not allowed \\
\hline Coliform bacteria $(\mathrm{CFU} / \mathrm{g})$ & not found & not found & Not allowed \\
\hline
\end{tabular}

Here sample G1 - HPMC made by Acros (Belgium); sample G2 - HPMC made by Ashland Aqualon Functional Ingredients (USA)

materials CAS 9004-65-3. In case of viscosity, strength of jelly and transparency both used HPMS sample show superiority over the recommendation of CAS 9004-65-3.

Results of HPMC chemical and microbiological safety testing have been presented in table 6 . Result of study revealed that both samples of HPMC meet the safety requirements of CAS 9004-653. The contents of lead, cadmium, arsenic, mercury, mesophilic aerobic and facultative anaerobic microorganisms, coliforms, bacteria of group proteus, and pathogenic microorganisms do not exceed the maximum permissible concentration. Among the tested two samples G1 (HPMC made by Acros, Belgium) have better properties as compared to sample G2 (HPMC made by Ashland Aqualon Functional Ingredients, USA) but no significant difference was found among these two.

The results of physico-chemical properties of gelatin (sample G1 and G2) have been given in Table 7. Both the used samples meet the criteria specified by GOST 23058-89 in their physicochemical parameters. Like HPMC, gelatin also performed better than the criteria prescribed by GOST 23058-89 and show good viscosity, strength of jelly and transparency. Further, gelatin have higher melting point which support it use as packaging material.

Chemical and microbiological safety of gelatin have been tested and reported that heavy metals, toxic elements, radionuclides, residual pesticides and microbiological parameters are in the range of GOST 23058-89 prescription (Table 8). The data in the table show that both samples of gelatin by their physico-chemical properties and safety indicators meet the requirements of GOST 23058-89. Further, contents of lead, cadmium, arsenic, mercury, mesophilic aerobic, facultative anaerobic microorganisms, coliforms, bacteria of group proteus, and pathogenic microorganisms are in the range of acceptance as it can use as packaging materials. 
Table 7: Physico-chemical characteristics of gelatin

\begin{tabular}{|c|c|c|c|}
\hline \multirow{2}{*}{ Indicator name } & \multicolumn{2}{|c|}{ Sample } & \multirow{2}{*}{$\begin{array}{l}\text { Requirements of GOST } \\
23058-89\end{array}$} \\
\hline & Sample J1 & Sample J2 & \\
\hline Duration of dissolution (min) & $20.0 \pm 1.0$ & $22.0 \pm 1.1$ & not more than 25.0 \\
\hline Mass fraction of moisture (\%) & $12.9 \pm 0.5$ & $13.0 \pm 0.5$ & not more than 16.0 \\
\hline Mass fraction of ash in terms of absolutely dry gelatin (\%) & $1.0 \pm 0.1$ & $0.9 \pm 0.1$ & not more than 1.5 \\
\hline $\begin{array}{l}\text { Decreased viscosity of the solution with the mass fraction of } \\
\text { gelatin of } 10 \%(\%)\end{array}$ & $11.5 \pm 0.6$ & $12.0 \pm 0.6$ & not more than 15.0 \\
\hline $\begin{array}{l}\text { Dynamic viscosity of a solution with the mass fraction of gelatin } \\
\text { of } 10 \% \text {, in terms of absolutely dry gelatin (MPa } s)\end{array}$ & $25.0 \pm 1.2$ & $26.5 \pm 1.3$ & not less than 24.6 \\
\hline $\begin{array}{l}\text { Strength of jelly with the mass fraction of gelatin of } 10 \% \text {, in terms } \\
\text { of absolutely dry ash-free gelatin, } \mathrm{N}(\mathrm{gs})\end{array}$ & $14.7 \pm 0.7$ & $15.0 \pm 0.8$ & Not less than 13.0 \\
\hline $\begin{array}{l}\text { Transparency of the solution with the mass fraction of gelatin of } \\
5 \%(\%)\end{array}$ & $75.0 \pm 3.8$ & $80.0 \pm 4.0$ & Not less than 70.0 \\
\hline $\begin{array}{l}\text { The melting point of the jelly with the mass fraction of gelatin of } \\
10 \% \text {, in terms of absolutely dry ash-free gelatin }\left({ }^{\circ} \mathrm{C}\right)\end{array}$ & $33.0 \pm 1.7$ & $35.2 \pm 1.8$ & not less than 32.0 \\
\hline $\mathrm{pH}$ of the solution with mass share of gelatin of $1 \%$ & $5.5 \pm 0.5$ & $5.7 \pm 0.6$ & $5.2-6.1$ \\
\hline
\end{tabular}

Here sample J1 - gelatin made by "Minvody Gelatin Plant" (Russia); sample J2 - gelatin made by "GelatinesWeishardt" (France)

Table 8 Indicators of chemical and microbiological safety of gelatin

\begin{tabular}{|c|c|c|c|}
\hline Indicator name & Sample J1 & Sample J2 & $\begin{array}{c}\text { Requirements of GOST } \\
23058-89\end{array}$ \\
\hline Sulphurous acid (in equivalent to $\mathrm{SO} 2, \%$ ) & $0.010 \pm 0.001$ & below the determination limit & no more than 0.060 \\
\hline Zinc $(\mathrm{mg} / \mathrm{kg})$ & $10.00 \pm 0.50$ & $20.00 \pm 1.00$ & not more than 100.00 \\
\hline Lead (mg/kg) & $0.15 \pm 0.01$ & $0.08 \pm 0.01$ & not more than 2.00 \\
\hline Cadmium (mg/kg) & below the determination limit & $0.010 \pm 0.005$ & not more than 0.030 \\
\hline Copper $(\mathrm{mg} / \mathrm{kg})$ & below the determination limit & below the determination limit & not more than 15.00 \\
\hline Arsenic $(\mathrm{mg} / \mathrm{kg})$ & $0.010 \pm 0.005$ & $0.010 \pm 0.005$ & no more than 0.500 \\
\hline Mercury $(\mathrm{mg} / \mathrm{kg})$ & below the determination limit & below the determination limit & not more than 0.02 \\
\hline $\begin{array}{l}\text { Mesophilic aerobic and facultative } \\
\text { anaerobic microorganisms } \\
\text { (cells in } 1 \mathrm{~g} \text { of gelatin) }\end{array}$ & $0.9 \cdot 10^{2}$ & $3.2 \cdot 10^{2}$ & not more than $1.0 \cdot 10^{3}$ \\
\hline Coliform bacteria (cells per $1 \mathrm{~g}$ of gelatin) & not found & not found & not allowed \\
\hline Protea group bacteria & not found & not found & not allowed \\
\hline $\begin{array}{l}\text { Gelatin containing bacteria } \\
\text { (cells per } 1 \mathrm{~g} \text { of gelatin) }\end{array}$ & not found & not found & not allowed \\
\hline Pathogens & not found & not found & not allowed \\
\hline
\end{tabular}

Here sample J1 - gelatin made by "Minvody Gelatin Plant" (Russia); sample J2 - gelatin made by "GelatinesWeishardt" (France)

Gelatine and natural polysaccharides were used in various concentration and total 21 combination were prepared which were assigned sample number 1-21 (table 9). All the predescribed packaging material combination were mixed in required amount of distilled water and heat upto dissolution. After dissolution, the mixture of components was kept on the heating mantle, the temperature of the mixer was $150{ }^{\circ} \mathrm{C}$, the rotation speed was 800 $\mathrm{rpm}$; the resulting solution was poured on a substrate with sides 2 $\mathrm{mm}$ thick; drying was performed in a drying cabinet at $85{ }^{\circ} \mathrm{C}$ (Table 9).

Result of drying gelatin-based solutions and natural polysaccharides

\section{Journal of Experimental Biology and Agricultural Sciences} http://www.jebas.org 
Table 9 Composition of studied gelatin-based films and natural polysaccharides

\begin{tabular}{|c|c|c|c|c|c|}
\hline \multirow{2}{*}{ Sample number } & \multicolumn{5}{|c|}{ Amount of the ingredient (wt. \%) } \\
\hline & Carageenan & HPMC & Agar-agar & Gelatin & Water \\
\hline 1 & 5.0 & 2.5 & - & 5.0 & 87.5 \\
\hline 2 & 10.0 & 2.5 & - & 10.0 & 77.5 \\
\hline 3 & 5.0 & 5.0 & - & 51.0 & 39.0 \\
\hline 4 & 10.0 & 5.0 & - & 5.0 & 80.0 \\
\hline 5 & 5.0 & 10.0 & - & 30.0 & 55.0 \\
\hline 6 & 10.0 & 10.0 & - & 51.0 & 29.0 \\
\hline 7 & 5.0 & - & 2.5 & 5.0 & 87.5 \\
\hline 8 & 10.0 & - & 2.5 & 10.0 & 77.5 \\
\hline 9 & 5.0 & - & 5.0 & 30.0 & 60.0 \\
\hline 10 & 10.0 & - & 5.0 & 51.0 & 34.0 \\
\hline 11 & 5.0 & - & 10.0 & 51.0 & 34.0 \\
\hline 12 & 10.0 & - & 10.0 & 10.0 & 70.0 \\
\hline 13 & - & 2.5 & 2.5 & 5.0 & 90.0 \\
\hline 14 & - & 10.0 & 2.5 & 10.0 & 77.5 \\
\hline 15 & - & 5.0 & 10.0 & 10.0 & 75.0 \\
\hline 16 & 5.0 & 2.5 & 10.0 & 51.0 & 31.5 \\
\hline 17 & 10.0 & 2.5 & 2.5 & 10.0 & 75.0 \\
\hline 18 & 5.0 & 5.0 & 5.0 & 5.0 & 80.0 \\
\hline 19 & 10.0 & 5.0 & 5.0 & 10.0 & 70.0 \\
\hline 20 & 5.0 & 10.0 & 10.0 & 30.0 & 45.0 \\
\hline 21 & 10.0 & 10.0 & 10.0 & 10.0 & 60.0 \\
\hline
\end{tabular}

Table 10 Results of drying gelatin-based solutions and natural polysaccharides

Sample number Result of drying

\begin{tabular}{|cl|}
\hline 1 & The film was not obtained due to low components' concentrations \\
\hline 2 & High-quality film could not be obtained; there are undissolved HPMC particles \\
\hline $\mathbf{3}$ & Transparent and elastic films of uniform thickness \\
\hline 4 & High-quality film could not be obtained; there are undissolved HPMC particles \\
\hline 5 & The obtained samples are fragile and have brittle structure. It is inappropriate to use them for further research \\
\hline 6 & The obtained samples are fragile and have brittle structure. It is inappropriate to use them for further research \\
\hline 7 & The obtained samples are fragile and have brittle structure. It is inappropriate to use them for further research \\
\hline
\end{tabular}




\begin{tabular}{|c|c|}
\hline Sample number & Result of drying \\
\hline 8 & $\begin{array}{l}\text { The obtained films have uneven thickness due to high viscosity of the solution. It is inappropriate to use them for } \\
\text { further research }\end{array}$ \\
\hline 9 & The obtained samples are fragile and have brittle structure. It is inappropriate to use them for further research \\
\hline 10 & $\begin{array}{l}\text { The obtained films have uneven thickness due to high viscosity of the solution. It is inappropriate to use them for } \\
\text { further research }\end{array}$ \\
\hline 11 & Transparent and elastic films of uniform thickness \\
\hline 12 & $\begin{array}{l}\text { The obtained films have uneven thickness due to high viscosity of the solution. It is inappropriate to use them for } \\
\text { further research }\end{array}$ \\
\hline 13 & Plasticity and flexibility of the films are missing, therefore, it is impractical to use them for further research \\
\hline 14 & Transparent and elastic films of uniform thickness \\
\hline 15 & Plasticity and flexibility of the films are missing, therefore, it is impractical to use them for further research \\
\hline 16 & Transparent and elastic films of uniform thickness \\
\hline 17 & $\begin{array}{l}\text { The obtained films have uneven thickness due to high viscosity of the solution. It is inappropriate to use them for } \\
\text { further research }\end{array}$ \\
\hline 18 & Transparent and elastic films of uniform thickness \\
\hline 19 & $\begin{array}{l}\text { The obtained films have uneven thickness due to high viscosity of the solution. It is inappropriate to use them for } \\
\text { further research }\end{array}$ \\
\hline 20 & Transparent and elastic films of uniform thickness \\
\hline 21 & lity of the films are missing, therefore, it is impractical to use them for further research \\
\hline
\end{tabular}

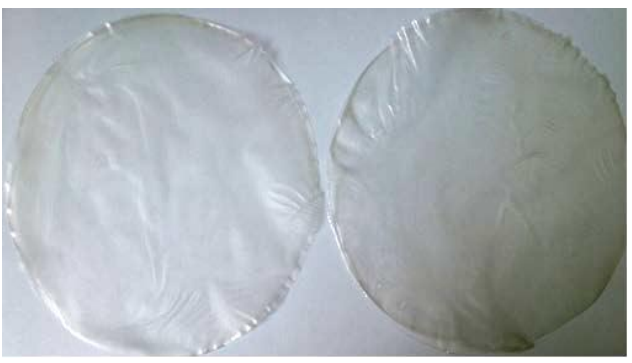

a
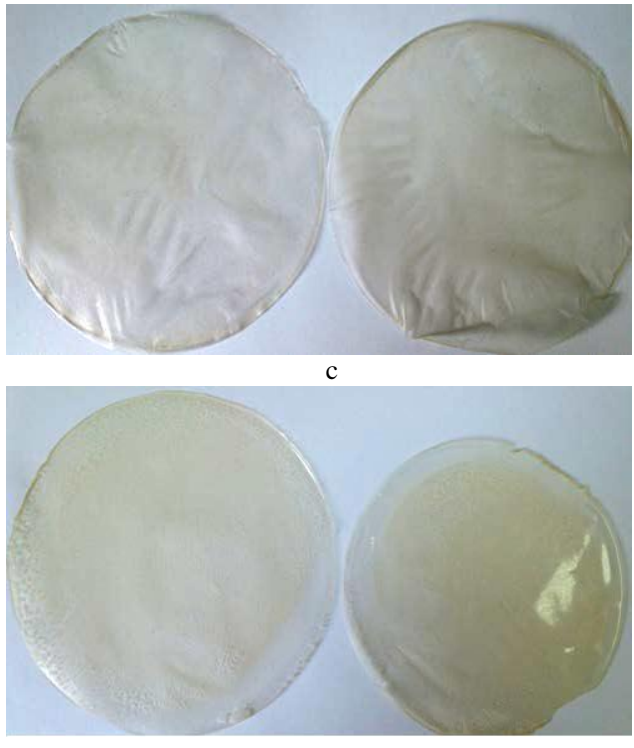

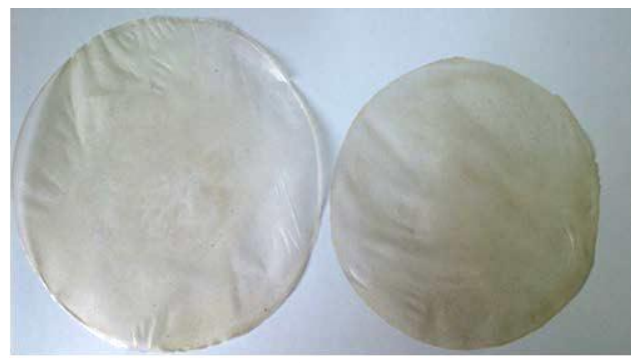

b

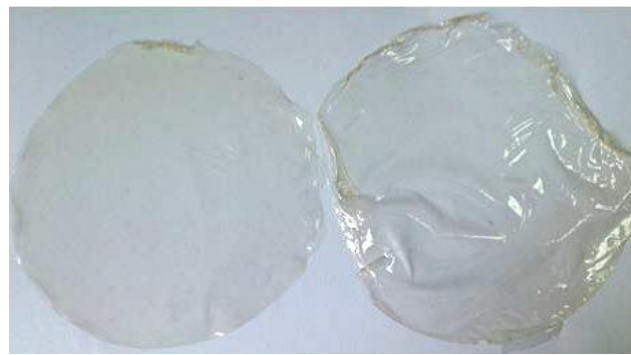

d

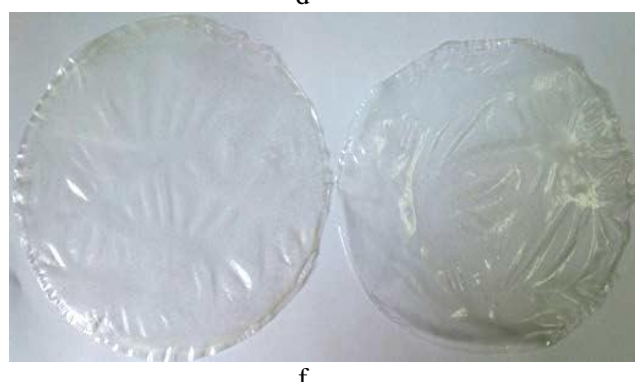

$\mathrm{f}$

Figure 1 Photos of the studied films sample No. 3 (a); sample No. 11 (b); sample No. 14 (c); sample No. 16 (d); sample No. 18 (e) and sample No. 20 (f)

Journal of Experimental Biology and Agricultural Sciences http://www.jebas.org 
Table 11 Characteristics of gelatin and natural polysaccharides based packaging materials obtained using various technological methods

\begin{tabular}{|c|c|c|c|}
\hline \multirow[t]{2}{*}{ Indicator Name } & \multicolumn{3}{|c|}{ Value of the indicator for packaging materials obtained by various processing methods } \\
\hline & Extrusionblowing & thermoforming & extrusion blowing forming \\
\hline \multicolumn{4}{|c|}{ Sample No. 3} \\
\hline Tensile strain $\sigma p, \mathrm{MPa}$ & $56.8 \pm 5.7$ & $15.0 \pm 1.5$ & $32.6 \pm 3.3$ \\
\hline Strain-to-failure, $\varepsilon p, \%$ & $10.0 \pm 1.0$ & $1.2 \pm 0.1$ & $5.4 \pm 0.5$ \\
\hline Elasticity modulus, $\mathrm{MPa}$ & $2,550 \pm 255$ & $550 \pm 55$ & $1,250 \pm 125$ \\
\hline Gas permeability, $\mathrm{cm}^{3} / \mathrm{m}^{2} \cdot 24 \mathrm{~h} \cdot \mathrm{atm}$ & $246.000 \pm 24.600$ & $5.665 \pm 0.567$ & $75.006 \pm 7.501$ \\
\hline \multicolumn{4}{|c|}{ Sample No. 11} \\
\hline Tensile strain $\sigma \mathrm{p}, \mathrm{MPa}$ & $88.3 \pm 8.8$ & $13.8 \pm 1.4$ & $25.5 \pm 2.6$ \\
\hline Strain-to-failure, $\varepsilon p, \%$ & $7.7 \pm 0.8$ & $2.0 \pm 0.2$ & $6.0 \pm 0.6$ \\
\hline Elasticity modulus, $\mathrm{MPa}$ & $1,800 \pm 180$ & $400 \pm 40$ & $980 \pm 98$ \\
\hline Gas permeability, $\mathrm{cm}^{3} / \mathrm{m}^{2} \cdot 24 \mathrm{~h} \cdot \mathrm{atm}$ & $310.002 \pm 31.000$ & $8.124 \pm 0.812$ & $115.225 \pm 11.523$ \\
\hline \multicolumn{4}{|c|}{ Sample No. 14} \\
\hline Tensile strain $\sigma \mathrm{p}, \mathrm{MPa}$ & $63.7 \pm 6.4$ & $11.9 \pm 1.2$ & $22.1 \pm 2.2$ \\
\hline Strain-to-failure, $\varepsilon p, \%$ & $9.5 \pm 1.0$ & $1.5 \pm 0.1$ & $3.9 \pm 0.4$ \\
\hline Elasticity modulus, MPa & $3,300 \pm 330$ & $780 \pm 78$ & $1,100 \pm 110$ \\
\hline Gas permeability, $\mathrm{cm}^{3} / \mathrm{m}^{2} \cdot 24 \mathrm{~h} \cdot \mathrm{atm}$ & $285.015 \pm 28.502$ & $6.075 \pm 0.608$ & $80.905 \pm 8.091$ \\
\hline \multicolumn{4}{|c|}{ Sample No. 16} \\
\hline Tensile strain $\sigma \mathrm{p}, \mathrm{MPa}$ & $72.5 \pm 7.3$ & $9.5 \pm 1.0$ & $34.0 \pm 3.4$ \\
\hline Strain-to-failure, $\varepsilon p, \%$ & $7.5 \pm 0.8$ & $1.0 \pm 0.1$ & $4.4 \pm 0.4$ \\
\hline Elasticity modulus, $\mathrm{MPa}$ & $3100 \pm 310$ & $390 \pm 39$ & $1500 \pm 150$ \\
\hline Gas permeability, $\mathrm{cm}^{3} / \mathrm{m}^{2} \cdot 24 \mathrm{~h} \cdot \mathrm{atm}$ & $324,005 \pm 32,401$ & $8,125 \pm 0,813$ & $111,325 \pm 11,133$ \\
\hline \multicolumn{4}{|c|}{ Sample No. 18} \\
\hline Tensile strain $\sigma \mathrm{p}, \mathrm{MPa}$ & $67.0 \pm 6.7$ & $14.4 \pm 1.4$ & $37.2 \pm 3.7$ \\
\hline Strain-to-failure, $\varepsilon p, \%$ & $11.1 \pm 1.1$ & $2.8 \pm 0.3$ & $5.2 \pm 0.5$ \\
\hline Elasticity modulus, $\mathrm{MPa}$ & $2700 \pm 270$ & $520 \pm 52$ & $675 \pm 68$ \\
\hline Gas permeability, $\mathrm{cm}^{3} / \mathrm{m}^{2} \cdot 24 \mathrm{~h} \cdot \mathrm{atm}$ & $415,007 \pm 41,501$ & $10,122 \pm 1,012$ & $100,045 \pm 10,005$ \\
\hline \multicolumn{4}{|c|}{ Sample No. 20} \\
\hline Tensile strain $\sigma \mathrm{p}, \mathrm{MPa}$ & $72.0 \pm 7.2$ & $10.2 \pm 1.0$ & $28.4 \pm 2.8$ \\
\hline Strain-to-failure, $\varepsilon p, \%$ & $8.8 \pm 0.9$ & $1.9 \pm 0.2$ & $6.1 \pm 0.6$ \\
\hline Elasticity modulus, $\mathrm{MPa}$ & $1450 \pm 145$ & $645 \pm 65$ & $800 \pm 80$ \\
\hline Gas permeability, $\mathrm{cm}^{3} / \mathrm{m}^{2} \cdot 24 \mathrm{~h} \cdot \mathrm{atm}$ & $500,009 \pm 50,001$ & $9,005 \pm 0,900$ & $85,165 \pm 8,517$ \\
\hline
\end{tabular}

film formulation have been presented in table 10. As per the used combinations, only six samples of gelatin-based films and natural polysaccharides $(3,11,14,16,18$ and 20$)$ can formed transparent and elastic flim with uniform thickness. Above said combination used for further study while rest of the combination were discard from the further study (Figure 1, Table 10).

The results of determining structural and mechanical properties along with strength and gas permeability of the obtained samples $(3,11,14,16,18 \& 20)$ have been given in Table 11. 


\section{Discussion}

Packaging is an important element for preserving food quality. According to the normative documentation, a developer of new products should take care of consumer properties and safety, their hygienic standards, requirements for ensuring compliance with specified regulations in the process of production, storage, transportation and sales. In addition, packaging material that contacts food products should have certain adaptability to manufacturing and use, as well as fuel efficiency, reliability, strength, attractiveness and, most importantly, be comfortable for the consumer.

To choose the optimal composition of biodegradable polymers, the following samples of gelatin and natural polysaccharides were chosen based on the studies for determining their physicochemical properties and safety: agar (Helicon, USA), Kappacarrageenan (Boc Sciences, USA), hydroxypropylmethylcellulose (Ashland Aqualon Functional Ingredients, USA), gelatin ("Gelatines Weishardt", France). By the indicators of chemical and microbiological safety, all studied samples of gelatin comply with the current hygienic standards. Result of present study are in agreement with the finding and suggestion of Lu et al. (2010); Liu (2010); Rhim (2012); Liu (2015) and Razavi (2016).

In this regard, for further development of the technology of obtaining biodegradable polymers, it is advisable to use any presented samples of natural polysaccharides and gelatin as the components.

\section{Conclusion}

Physico-chemical properties and safety indicators of gelatin and natural polysaccharides (agar, carageenan, hydroxypropymethylcellulose - HPMC) have been studied. It has been shown that in terms of quality and safety, all tested samples satisfy the requirements of the applicable documentation. With the aim of finding the optimal composition of biodegradable packaging materials based on gelatin and natural polysaccharides, film samples have been obtained.

\section{Conflict of Interest}

Authors would hereby like to declare that there is no conflict of interests that could possibly arise

\section{References}

Khan A, Huq T, Khan RA, Riedl B, Lacroix M (2014). Nanocellulose-Based Composites and Bioactive Agents for Food Packaging. Critical Reviews in Food Science and Nutrition 54: $163-174$

Kisku SK, Swain SK (2012) Study of oxygen permeability and flame retardancy properties of biodegradable polymethylmethacrylate. Polymer Composites 33: 79-84.

Liu M (2010) Analysis of biodegradability of biodegradable mulching films. Journal of Polymers and the Environment 18: 148-154.

Liu SJ (2015) Rheological Properties and Scaling Laws of kappaCarrageenan in Aqueous Solution. Macromolecules 20: 76497657.

Lu G, Peng X, Sun L, Wang P, Zhu G (2010) Patent 101812188A China, MPK 08 K 13/06. Method for preparing starch-based bioresin suitable for blowing films; the applicant and the patentee Gangdongshangjiu biodegradable plastics CO LTD. No.CN201019050014 20100202; stat. 02.02.2010; publish. 2.02.2010.

Pantyukhov PV (2012a) Interaction of natural fillers with polyethylene matrix in biodegradable polymer compositions. Proceedings of the XII Annual International Conference of Biochemical Physics RAS-Universities "Biochemical Physics" held on 13-15 January,2012 at Moscow, Pp. 131-133.

Pantyukhov PV (2012b) The oxidative and biological destruction of composite materials based on low-density polyethylene and lignocellulosic fillers. Chemistry and Chemical Technology $6: 349-354$

Razavi SMA (2016) Structural and physicochemical characteristics of a novel water-soluble gum from Lallemantiaroyleana seed. International Journal of Biological Macromolecules, 83: 142-151.

Rhim JW (2013) Bio-nanocomposites for food packaging applications. Progress in Polymer Science 38: 1629-1652.

Schreiber SB, Bozell JJ,Hayes DG, Zivanovic SV (2013) Introduction of primary antioxidant activity to chitosan for application as a multifunctional food packaging material. Food Hydrocolloids 33: 207-214. 